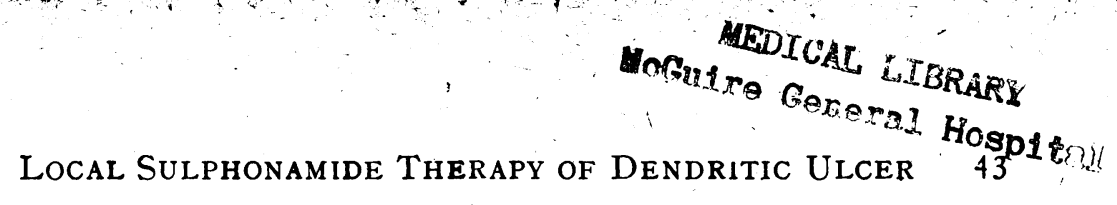

say 2 weeks later, the ulcer would inflame again, and we would be compelled to cover the cornea again, as has happened. Even 2-3 months later we have seen a weak relapse with a small hypopyon for a few days. As far as our observations go, the interval of at least 6 months has to be kept. It is surprising, how willingly our patients wait, till the set term is over.

The re-opening is a simple procedure. We lift the conjunctiva somewhere on the cornea, make a hole in it through which we introduce the scissors and cut away the flap all around inside the limbus. The parts grown together are detached as a pseudopterygium by iris-spatula and keratome. One has to take care not to leave a thin capsular layer on the cornea. The eye is dressed for 1 to 3 days.

Encouraged by the satisfactory results, recently we have begun to extend considerably the sphere of application of the total hooding, i.e., to all acute and chronic keratitic processes unhealed or not healing well, such as ulcerated and degenerated pannus, ulcus destruens, herpes corneae, kerato-mycosis, neuroparalytic keratitis. Once we applied it to an enormous exophthalmos in Graves' disease with excellent result.

Thus the total conjunctival hooding of the cornea became at my clinic an increasingly employed proceeding for keratitic processes and it is my firm conviction that we can save eyes by it, that would be otherwise inevitably lost.

\title{
REFERENCES
}

1. Kettesy, A.-(Kreiker): Vollstandige Bindehautdeckung der Hornhaut, etc., Klin. Monatsbl. f. Augenheilk., Vol. XC, p. 373,1933.

2. A. Miklós.-Behandlung des Ulcus serpens etc., Klin. Monatsbl. f. Augenheilk., Vol. CVII, p. 138, 1941.

3. LAwaetz.-Zentralbl.f. die ges: Ophthal., 1943.

4. Threl.-Augenärztl. Operations. Thieme, 1942.

\section{LOCAL SULPHONAMIDE THERAPY OF DENDRITIC ULCER*}

BY

\section{H. L. HUGHES}

LONDON

IN the early days of sulphonamide therapy Kleefeld (1938) recorded favourable results from the general administration of the drug in six cases of dendritic ulceration and in twenty cases of corneal herpes. Schmid and Saubermann (1942) likewise obtained satisfactory results in five out of twenty-one cases of herpes corneae. Most 
observers, however, have had a less favourable experience but Sorsby (1944) has drawn attention to the value of local therapy in dendritic ulcer. He reported unexpectedly encouraging results from the intensive use of local sulphonamide therapy in sixteen consecutive cases. Improvement was generally rapid and most eyes, though not fully cured, were symptomless within ten to fourteen days.

\section{A Series of 16 cases}

Clinical features.-Local therapy was employed in a series of sixteen consecutive cases seen during January-April, 1947. The clinical details are set forth in Table I. It will be noted that twelve cases out of sixteen responded to treatment, and that in six of these twelve cases, the response was particularly good. The cases showing a good response (Nos. $1-6$ in Table I) showed the following features :-

(1) Morphologically the ulcers were all small, typical dendritic figures occupying an area about $1 \times 1 \frac{1}{2} \mathrm{~mm}$. in an otherwise healthy looking cornea.

(2) Sensation was diminished in three cases, normal in two, and appeared relatively increased in one.

(3) The duration of the symptoms before treatment varied from $7-21$ days, and all cases were clinically cured within 8 days.

The six cases that gave a fair response, varied from the first group in that:

(1) The ulcers were more extensive. In two cases the dendritic figure appeared upon a cornea the seat of pre-existing ulceration of long duration.

(2) Sensation was diminished in all cases, and in three remained absent throughout treatment. In the remaining three it was very slow in returning.

(3) The duration of the symptoms before treatment varied from $2-10$ days. The total duration of treatment was from $14-28$ days, but the cases were all asymptomatic in 6-13 days.

The last group of four cases included one which was identical clinically with those of Group 1, whilst three had much more marked corneal involvement, varying from multiple punctate opacities to generalised oedema of the cornea. Case No. 16 was associated with German measles and showed a severe lesion.

\section{Mode of Treatment}

Six per cent. albucid ointment (Schering) was instilled thrice daily, and the entire corneal surface painted once daily with $30 \%$ albucid solution. This necessitated a daily attendance.

As may be seen from Table I, the subsidence of acute symptoms was rapid in successful cases, and the eye rapidly became white. 
Local Sulphonamide Therapy of Dendritic Ulcer 45

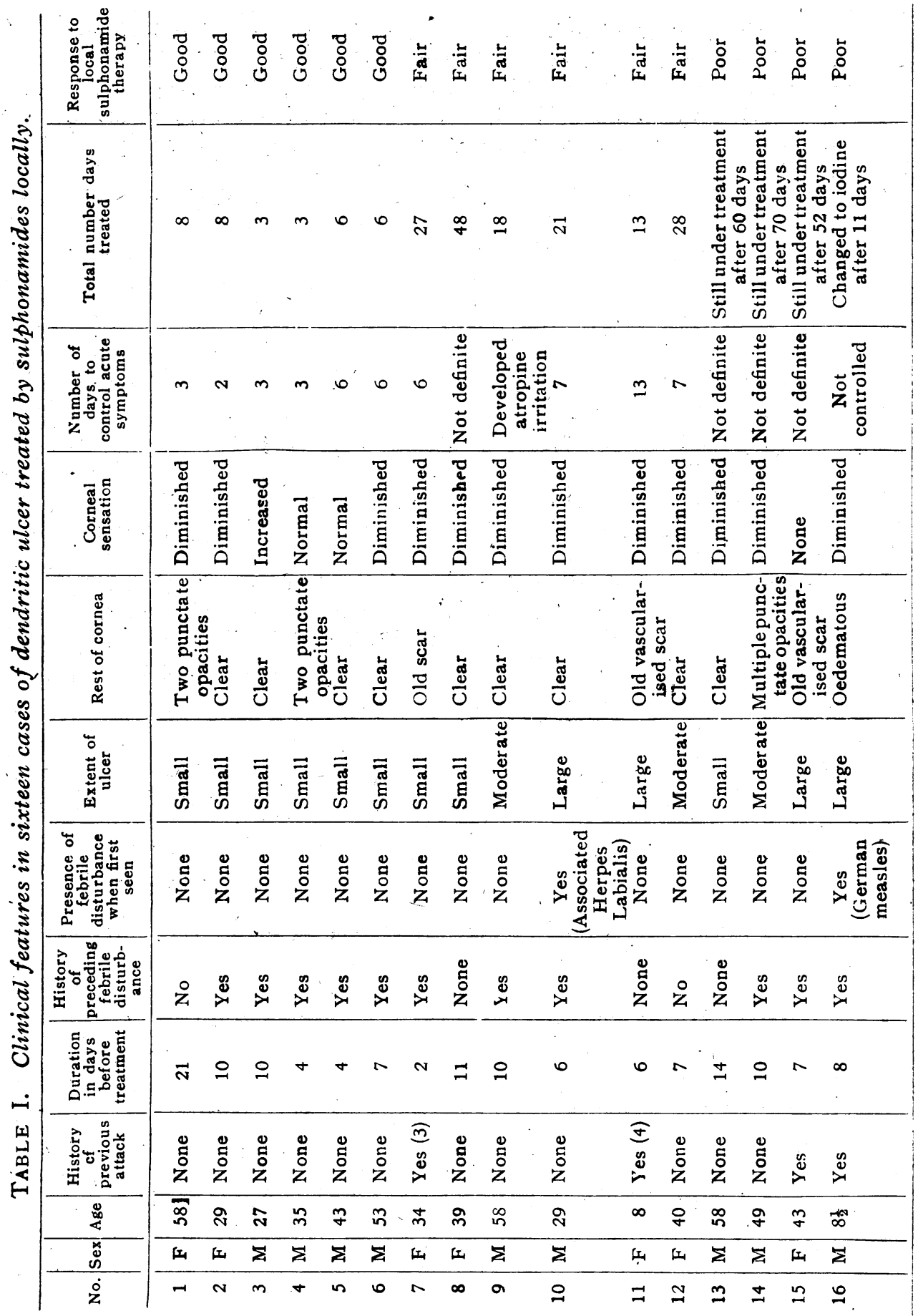


Routine guttae atropine $1 \%$ daily, and a pad and bandage was used in all cases. The cases that were not controlled by local sulphonamide were treated by iodine cauterisation. The response to iodine therapy in Case No. 16 (associated with German measles) was dramatic, after 11 days treatment without any obvious response to albucid.

Prognosis.-Clinically the cases fall into three categories. In the first the lesion is superficial and does not appear to penetrate beyond Bowman's membrane. On painting such a case the characteristic figure is removed and a diffuse stain is left. This healed rapidly under the local therapy.

In the second group the lesion goes deeper into the substantia propria, and the dendriform figure can still be made out after removal of all loose epithelium. Thése cases took longer, but healed without severe scarring, though some scarring was always present.

In the third type there was diffuse opacity in the substantia propria. Whether arising de novo or superimposed upon an old corneal lesion these cases proved more difficult to treat.

The age of the patient did not appear to influence the type, activity, or response to treatment.

Corneal sensation rather than size of the ulcer seems to afford the best guide to the progress of the lesion. Cases with marked depression of sensation were slow to heal, and healing progressed parallel with the return of sensation. Cases with little or no loss of sensation when first seen responded rapidly.

\section{Theoretical Considerations}

Dendritic ulcer is regarded as a herpes virus infection. Theoretically it should not respond to sulphonamide therapy. As Sorsby points out the good results recorded by him (and confirmed in the present study), raise the question whether the current views on the aetiology of dendritic ulcer are valid. It is, of course, also possible that the high concentration reached by local treatment is effective against the virus.

My thanks are due to Professor Arnold Sorsby for the constant help and encouragement he has given me, and to the members of the staff of the Royal Eye Hospital who have helped me to obtain the material and assisted me in every possible way.

\section{REFERENCES}

Kleefeld, G. (1938)-Bull. Soc. Belge d'Ophtal. Vol. LXXVI, p. 14. SchMid and SAUBERMANN, (1942)-Ophthalmologica, Vol. CIII, p. 65. SorsBy, A. (1944)-Trans. Ophthal. Soc. U.K., Vol. LXIV, p. 75. 